\author{
Journal Of Medical Science And Clinical Research \\ IGM Publication \\ An Official Publication of IGM Publication
}

\title{
A Comparison of Effect of Metformin in Combination with Glimepiride and Glibenclamide on Glycaemic Control in Patients with Type 2 Diabetes Mellitus
}

\author{
Authors \\ Ujwala Gawali*1, Amruta Umathe ${ }^{2}$
}

${ }^{1}$ Department of Pharmacology, Dr. V.M. Government Medical College Solapur, Maharashtra, India

${ }^{2}$ Department of Pharmacology, Dr. V.M. Government medical college Solapur, Maharashtra, India

Corresponding Author

Ujwala Gawali

Associate Professor, Dept of Pharmacology, Dr. V.M. Government Medical College, Solapur, MH, India

Email id-ujwalagawali1963@gmail.com

\begin{abstract}
ObjectiveTo compare the effects of combination therapy using metformin and glimepiride with metformin and glibenclamide combination on glycaemic control ( $\mathrm{HbA}_{l c}$ and plasma glucose) and lipid profiles \{ Total cholesterol (TC), Triglyceride (TG), low density lipoprotein cholesterol $(L D L-C)$, High density lipoprotein cholesterol (HDL-C) \} in type 2 diabetes mellitus patients who have inadequately control with metformin and glibenclamide monotherapy.

Research Design and Methods Patients with type 2 diabetes mellitus, inadequately controlled with metformin and glibenclamide monotherapy were enrolled in the study. Eligible patients were randomized into two groups to receive combination of metformin plus glimepiride $(1000 \mathrm{mg}+2 \mathrm{mg})$ and metformin plus glibenclamide (1000mg+10mg) for 12 weeks. Primary efficacy end points were changes in fasting blood sugar (FBS) and postprandial blood sugar (PPBS) from baseline to 4weeks, 8weeks and 12weeks and changes in HbA $\mathrm{A}_{1 \mathrm{C}}$ from baseline to final assessment i.e. at 12 weeks. The secondary efficacy end point included changes in lipid profile from baseline to final assessment.

Results At the end of 12 weeks difference in reduction in fasting blood sugar( FBS) and Glycosylated haemoglobin $\left(H b A_{l c}\right)$ between the treatment groups was not statistically significant $(p>0.05)$.But reduction in postprandial blood sugar (PPBS) was statistically more significant in glimepiride and metformin group $(p<0.05)$. Changes in lipid profile parameter between the treatment groups not statistically significant. Both groups were well tolerated except hypoglycaemic events was more in glibenclamide and metformin combination group

Conclusion Both groups have similar effect on $F B S$ and $H b A_{1 C}$, whereas glimepiride and metformin combination therapy has superior effect on PPBS level reduction and significantly lesser incidence of hypoglycaemia. Increasing evidence support the importance of postprandial hyperglycaemia in glycaemic control with regard to the development of complications in the patients with diabetes. Data also indicates that postprandial hyperglycaemia may have greater effect on the development of cardiovascular complications compared with elevated fasting plasma glucose.

A more intensive approach by using metformin and glimepiride combination therapy in patients with type 2 diabetes mellitus inadequately controlled with metformin, glibenclamide monotherapy may improve the care of patients with diabetes and, ultimately, the outcome of these patients.

Key words: combination therapy,type 2diabetes mellitus, Metformin, glimepiride, glibenclamide.
\end{abstract}




\section{INTRODUCTION}

Diabetes Mellitus is one of the most common noncommunicable diseases with high incidence all over the world. Diabetes is undoubtedly one of the most challenging health problems in the $21^{\text {st }}$ century ${ }^{[1]}$

DM is a spectrum of common metabolic disorders, arising from a variety of pathogenic mechanisms, all resulting in hyperglycaemia. Factors contributing to it are insufficient insulin secretion, reduced responsiveness to insulin, increased glucose production and abnormalities in carbohydrate, fat and protein metabolism ${ }^{[2]}$.

DM is a chronic progressive illness that requires continuing medical care and proper patient selfmanagement education to prevent acute complications and also reduce risk of long term complications which occur over a period of time [3]

Globally as of 2010, it is estimated that there were about 285 million people with type $2 \mathrm{DM}$, making it nearly $90 \%$ of all types of diabetic cases, which is equivalent to $6 \%$ of world's population and the proportions are increasing at a fast pace ${ }^{[4]}$.

Goal of therapy in DM are directed towards attaining normoglycaemia, reducing the onset and progression of complications, treating comorbidities and improving quality and quantity of life ${ }^{[5]}$.Evidence based guidelines for the comprehensive management of diabetes focus primarily on lifestyle changes, management of cardiovascular disease risk factors and management of blood glucose levels ${ }^{[6]}$.

Conservative stepwise treatment approach initiated as monotherapy after failure of diet and exercise is changing to combination therapy as type $2 \mathrm{DM}$ have evidence of $50 \%$ reduction in beta cell function and $50 \%$ of normal insulin sensitivity, single drug therapy addresses only one, so it is not optimal ${ }^{[3]}$.

Combination therapy addresses both of them and aggressive treatment would improve patient outcomes while reducing overall health costs, it also makes therapeutic action to occur at lower doses and improves safety profile of drugs and early progression to combination therapy can maintain adequate control of blood glucose ${ }^{[7]}$. Clinical trials support the use of combination of antidiabetic agents with complementary mechanism of action such as sulphonylureas and metformin. It is a synergistic combination, sulphonylureas enhance insulin secretion whereas metformin acts to improve insulin sensitivity and suppress hepatic glucose output ${ }^{[8]}$.

Metformin should be included in therapy for type 2 DM patients, if tolerated and not contraindicated, as it is the oral hypoglycaemic medication proven to reduce risk of total mortality according to United Kingdom prospective diabetes study (UKPDS) ${ }^{[5]}$.

Combination treatment with metformin is more effective than sulphonylureas drugs alone in improving glycaemic control in type 2 diabetes, while also allowing a reduction of the dosage of each drug[9] Glibenclamide and metformin is the most common anti diabetic combination used in clinical practice ${ }^{[10]}$.

Glimepiride which is considered a third generation sulphonylurea agent has several beneficial pharmacological effects and side effects are less as compared to glibenclamide. ${ }^{3}$ Glimepiride may be associated with a reduced risk of myocardial damage compared with other SUS ${ }^{[11]}$.

So combination therapy of metformin and glimepiride is supposed to be one of the best treatments available for type $2 \mathrm{DM}$. So the aim of the present study was to compare the efficacy and safety of metformin plus glimepiride combination with metformin plus glibenclamide combination on glycaemic control in patients with type 2 DM.

\section{METHODS}

\section{Patients}

All patients of type $2 \mathrm{DM}$ presenting to diabetic clinic during study period were screened and those satisfying the inclusion and exclusion criteria were enrolled in the study.

The study was approved by Institutional ethics committee, written and Informed consent was 
taken from all the patients where every aspect of study was explained in detail in the language they were familiar with.

Patients who had failed on monotherapy with metformin (2000 mg/day) or glibenclamide (20 $\mathrm{mg} /$ day) and diagnosed as type $2 \mathrm{DM}$ cases as per American Diabetes Association diagnostic criteria's were included in the study. ${ }^{[12] .}$

Patients of type 1 diabetes mellitus, patients with current insulin therapy or received insulin for more than six weeks in last 3 months, known hypersensitivity to biguanides and sulfonylurea, patients on chronic medication known to affect glucose metabolism, patients with renal disease, congestive cardiac failure, hepatic insufficiency were excluded. History of myocardial infarction, stroke, patients suffering from visceral neuropathy, cancer, systemic lupus, erythematous lupus, HIV, pregnant and lactating mothers, patients of alcohol and drug abuse were excluded.

\section{Study design}

This prospective, randomized, open labelled study was conducted in diabetic OPD of a tertiary care teaching government hospital during the period of December 2012 to July 2014. 90 patients fulfilling inclusion and exclusion criteria were randomized into two groups.

Baseline parameters such as Fasting Blood Sugar (FBS), Postprandial Blood Sugar (PPBS), Glycosylated haemoglobin (HbA1c), lipid profile parameters like Total-Cholesterol (TC), Low Density Lipoprotein-Cholesterol (LDL-C), High Density Lipoprotein-Cholesterol (HDL-C) and Triglycerides $\left(\mathrm{TG}_{\mathrm{s}}\right)$ were assessed at the time of enrolment.

Eligible patients were randomized to receive glimepiride plus metformin $(1 \mathrm{mg}+500 \mathrm{mg} /$ day $)$ or Glibenclamide plus Metformin (5 mg+ 500 $\mathrm{mg} /$ day) for first 2 weeks. This was done to reduce the side effects and improve the tolerance of the patients as per the guidelines. After that the dose of glimepiride was increased to $2 \mathrm{mg} /$ day and metformin $1000 \mathrm{mg} /$ day in group 1 , and dose of glibenclamide was increased to $10 \mathrm{mg} /$ day and metformin $1000 \mathrm{mg} /$ day in group 2, for rest of duration of study.

\section{Study assessments and end points}

Study treatment was started on the day of randomization and continued for 12 weeks. FBS and PPBS were assessed at every visit, scheduled at 4 week intervals. Glycosylated haemoglobin (HbA1c) and Lipid profile [Total-C, LDL-C, HDL-C and TGs] were assessed at the time of enrolment and at final assessment. The primary efficacy end points were changes in mean levels of FBS and PPBS from baseline to 4 weeks, 8 weeks, and 12 weeks and changes in mean levels of $\mathrm{HbA} 1 \mathrm{c}$ from baseline to final assessment.

The secondary efficacy end point included changes in mean levels of lipid profile from baseline to final assessment. Safety outcomes included adverse events, particularly hypoglycaemic symptoms and other adverse events.

\section{Statistical analysis}

Unpaired ' $t$ ' test for difference between two means were used to analyse continuous variables at baseline and ' $z$ ' test for difference between two proportions were used to analyse categorical characteristics at baseline . Efficacy end points in both treatment groups were analysed by paired ' $t$ ' test. Efficacy end points between two treatment groups were analysed by unpaired' $t$ ' test. Safety outcomes in both treatment groups were analysed by ' $z$ ' test for difference between two proportions. In analysis, 'p' value $<0.05$ was considered statistically significant.

\section{RESULTS}

A total of 90 patients were enrolled in the study, 45 patients in glimepirideand other 45 patients in glibenclamide group. During the study period, 3 patients from glimepiride and 4 patients from Glibenclamide group were lost to follow up. Therefore, 42 patients in glimepiride and 41 patients in glibenclamide group were finally considered for analysis of data [Fig 1].

Baseline characteristics of both study groups which includes age, sex, BMI, weight, FBS, 
PPBS, HbA1c and lipid profile parameters. Both the groups were comparable for all the characteristics in the study and there was no statistically significant difference between the two groups ( $\mathrm{p}>0.05$ ) (Table 1).

Fasting blood sugar was significantly reduced in glibenclamide at 4 weeks and 8 weeks as compared to glimepiride and the difference is statistically significant. But at the end of 12 weeks, there is no significant difference between the two groups ( $p>0.05)$ (Table 2).

Postprandial blood sugar was significantly reduced in glimepiride group at 4 weeks, 8 weeks and 12 weeks as compared to glibenclamide and the difference is statistically significant $(\mathrm{p}<0.05)$ (Tab 3).

There was considerable decrease in both the groups in $\mathrm{HbA} 1 \mathrm{C} \%$ from baseline to 12 weeks but there was no statistically significant difference between both groups ( $p>0.05$ ) (Table 4$)$.

There was no stastistically significant changes in lipid profile in both the groups ( $>00.05)$ (Table 5). Adverse events were comparable in both the groups except in case of hypoglycaemia, the incidence of which was more in glibenclamide group and the difference was statistically significant $(\mathrm{p}<0.05)$ (Table 6).

Figure 1 Study profile

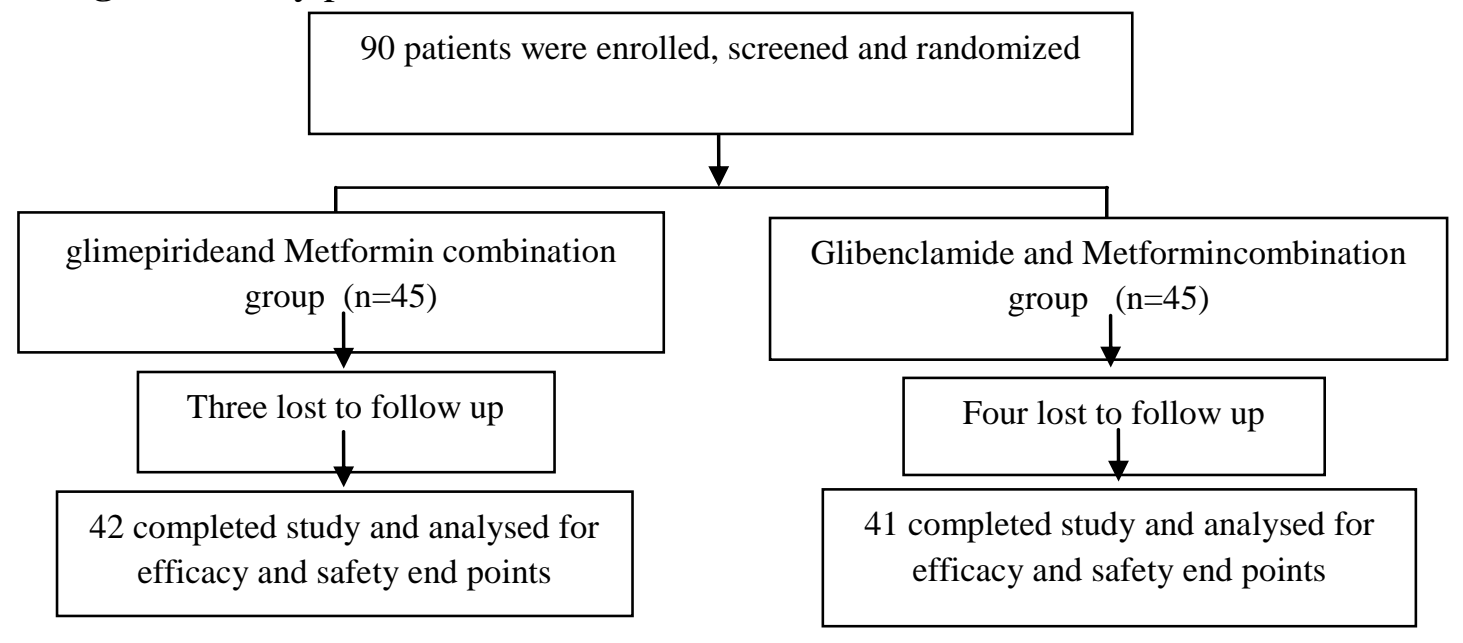

Table no. 1 Baseline characteristics of the study population

\begin{tabular}{|l|l|l|l|}
\hline Variables & $\begin{array}{l}\text { Glimepiride and metformin } \\
(\mathrm{n}=42)\end{array}$ & $\begin{array}{l}\text { glibenclamide and metformin } \\
(\mathrm{n}=41)\end{array}$ & P value \\
\hline Age $(\mathrm{yrs})$. & $52.78 \pm 6.50$ & $54.79 \pm 6.32$ & $>0.05$ \\
\hline Weight $(\mathrm{kgs})$. & $60.95 \pm 7.30$ & $59.90 \pm 6.35$ & $>0.05$ \\
\hline BMI $\left(\mathrm{kg} / \mathrm{m}^{2}\right)$ & $23.71 \pm 3.46$ & $24.77 \pm 3.66$ & $>0.05$ \\
\hline $\begin{array}{l}\text { Gender } \\
\text { Male }\end{array}$ & 26 & 24 & $>0.05$ \\
Female & 16 & 17 & $>0.05$ \\
\hline FBS $^{\#}(\mathrm{mg} / \mathrm{dl})$ & $176.83 \pm 17.70$ & $171.8 \pm 16.25$ & $>0.05$ \\
\hline PPBS $^{\$}(\mathrm{mg} / \mathrm{dl})$ & $250 \pm 23.30$ & $248.95 \pm 28.2$ & $>0.05$ \\
\hline
\end{tabular}




\begin{tabular}{|l|l|l|l|}
\hline $\mathrm{HbA}_{1 \mathrm{C}}(\%)$ & $9.37 \pm 0.77$ & $9.66 \pm 0.96$ & $>0.05$ \\
\hline $\begin{array}{l}\text { Lipid profile } \\
(\mathrm{mg} / \mathrm{dl})\end{array}$ & $184.69 \pm 23.60$ & $188.34 \pm 23.54$ & $>0.05$ \\
$\begin{array}{l}\text { Total } \\
\text { cholesterol }\end{array}$ & $91.95 \pm 5.4$ & $91.90 \pm 5.46$ & $>0.05$ \\
LDL-C $^{€}$ & $39.59 \pm 3.93$ & $41.21 \pm 4.94$ & $>0.05$ \\
HDL-C $^{£}$ & $166 \pm 12.88$ & $168 \pm 16.17$ & $>0.05$ \\
TGs $^{\odot}$ & & & \\
\hline
\end{tabular}

$\mathrm{z}$ test for gender, unpaired $\mathrm{t}$ test for other variables. Figures are expressed as mean $\pm \mathrm{SD}$.

\# fasting blood sugar,\$ postprandial blood sugar,€ low density lipoproteins,£ high density lipoproteins,@ Triglycerides

Table no. 2 Fasting blood sugar in both groups

\begin{tabular}{|l|l|l|l|}
\hline $\begin{array}{l}\text { Duration of } \\
\text { Study }\end{array}$ & $\begin{array}{l}\text { glimepiride and } \\
\text { metformin group }\end{array}$ & $\begin{array}{l}\text { glibenclamide and } \\
\text { metformin group }\end{array}$ & $\mathrm{P}$ value \\
\hline Baseline & $176.83 \pm 17.69$ & $171.76 \pm 16.24$ & $>0.05$ \\
\hline 4 weeks & $162.43 \pm 18.54$ & $151.61 \pm 16^{*}$ & $<0.05$ \\
\hline 8 weeks & $149.6 \pm 15.01$ & $135.37 \pm 12.96^{*}$ & $<0.05$ \\
\hline 12 weeks & $123.4 \pm 17.36$ & $121.07 \pm 15.7$ & $>0.05$ \\
\hline
\end{tabular}

Unpaired $\mathrm{t}$ test, $*_{-} \mathrm{P}<0.05$ Figures are Mean \pm Standard Deviation

Table no. 3postprandial blood sugar in both groups.

\begin{tabular}{|l|l|l|l|}
\hline $\begin{array}{l}\text { Duration of } \\
\text { Study }\end{array}$ & $\begin{array}{l}\text { glimepiride and } \\
\text { metformin group }\end{array}$ & $\begin{array}{l}\text { glibenclamide and } \\
\text { metformin group }\end{array}$ & P value \\
\hline Baseline & $250 \pm 23.30$ & $248.95 \pm 28.19$ & $>0.05$ \\
\hline 4 weeks & $212.86 \pm 20.69^{*}$ & $224.66 \pm 29.51$ & $<0.05$ \\
\hline 8 weeks & $191.83 \pm 19.28^{*}$ & $202.37 .93 \pm 28.77$ & $<0.05$ \\
\hline 12 weeks & $16945 \pm 16.56^{*}$ & $179.05 .49 \pm 25.47$ & $<0.05$ \\
\hline
\end{tabular}

Unpaired t test, $*_{-} \mathrm{P}<0.05$ Figures are Mean \pm Standard Deviation 
Table no. $4 \mathrm{HbA}_{1 \mathrm{C}}$ between the groups from baseline to 12 weeks.

\begin{tabular}{|l|l|l|l|}
\hline $\begin{array}{l}\text { Duration of } \\
\text { Study }\end{array}$ & $\begin{array}{l}\text { Glimepiride and } \\
\text { metformin }\end{array}$ & $\begin{array}{l}\text { Glibenclamide } \\
\text { and metformin }\end{array}$ & P value \\
\hline Baseline & $9.37 \pm 0.77$ & $9.66 \pm 0.95$ & $>0.05$ \\
\hline 12 weeks & $8.56 \pm 0.75$ & $8.82 \pm 0.91$ & $>0.05$ \\
\hline
\end{tabular}

Unpaired $t$ test, Figures are Mean \pm Standard Deviation

Table no. 5 Lipid Profile in both groups at 12 weeks.

\begin{tabular}{|l|l|l|l|l|}
\hline & TOTAL-C & LDL-C & HDL-C & TGs \\
\hline Glimepiride and metformin & $177.98 \pm 24.00$ & $91.33 \pm 5.6$ & $39.73 \pm 3.40$ & $165.19 \pm 12.89$ \\
\hline Glibenclamide and metformin & $184.8 \pm 22.49$ & $91.65 \pm 5.46$ & $41.17 \pm 4.79$ & $167.8 \pm 16.40$ \\
\hline
\end{tabular}

Unpaired t test, Figures are Mean \pm Standard Deviation

Table no.6 Incidence of adverse events occurring among patients in both the groups over 12 weeks duration of study.

\begin{tabular}{|l|c|c|c|}
\hline Adverse Events & $\begin{array}{c}\text { glimepiride and } \\
\text { metformin }\end{array}$ & $\begin{array}{c}\text { glibenclamide } \\
\text { and metformin }\end{array}$ & P value \\
\hline Metallic taste & 3 & 4 & $>0.05$ \\
\hline Hypoglycaemia & 2 & $9 *$ & $<0.05$ \\
\hline Nausea & 3 & 8 & $>0.05$ \\
\hline Abdominal Pain & 4 & 4 & $>0.05$ \\
\hline Vomiting & 2 & 3 & $>0.05$ \\
\hline Diarrhoea & 1 & 2 & $>0.05$ \\
\hline Dizziness & 1 & 1 & $>0.05$ \\
\hline
\end{tabular}

\section{DISCUSSION}

In the present prospective, randomized, open labelled study efficacy for glycaemic control and tolerability of glimepiride and metformin Combination group was compared with that of glibenclamide and metformin combination group. The rationale for combining a metformin, which is a biguanide with that of sulphonylureas, i.e. glibenclamide and glimepiride is that, they have different mechanism of actions. Metformin suppresses hepatic gluconeogenesis to reduce

\section{$\mathrm{Z}$ test, ${ }^{*}$ - $\mathrm{P}<0.05$, figures expressed as numbers}

fasting glycaemia, and also increases peripheral glucose uptake, whereas sulfonylureas increase insulin release from the $\beta$-cells, and work as long as some amount of $\beta$-cell residual function is present. This therapy has been shown to provide synergistic effect in many studies and metaanalysis ${ }^{[14]}$.

Glibenclamide and metformin is the most widely used combination therapy for type 2 DM. Glimepiride which is a third generation sulphonylurea agent can be given once daily even 
side effects are less and may have potent antioxidative, anti-inflammatory and angiogenic properties and it may potentially repair tissue damage by decreasing the levels of toxic advanced glycosylation end products (AGE) and increasing colony-stimulating factors, these are its beneficial pharmacological effects over glibenclamide ${ }^{[15]}$. Glimepiride may be associated with a reduced risk of myocardial damage compared with other sulphonylureas ${ }^{[1]}$.

Several studies have demonstrated the antihyperglycaemic effectiveness of this combinations against the monotherapies but head to head trials of glimepiride and metformin combination versus glibenclamide and metformin combination are few. Combination therapies provide better glycaemic control than the monotherapy with either metformin, glibenclamide or glimepiride and these drugs are most cost effective among the antihyperglycaemic drugs ${ }^{[8,9,10]}$.

In our study we used combination of glimepiride 2 $\mathrm{mg}$ and metformin $1000 \mathrm{mg}$ once daily in one group and other group received $10 \mathrm{mg}$ glibenclamide and metformin $1000 \mathrm{mg}$ combination once daily for 12 weeks. Shimpi et al ${ }^{[13]}$, also used the same drug combination in same doses as our study for 12 weeks.

In our study we found that, there was statistically significant reduction in glycaemic control parameters like FBS, PPBS and HbA1c in both the groups. Similar findings were reported by Shimpi et al ${ }^{[13]}$ and Ortiz et al ${ }^{[10]}$.

In our study, we found no statistically significant difference between the glimepiride and glibenclamide with regards to FBS and HbA1c but there was statistically significant reduction in PPBS in glimepiride than the glibenclamide group at 12 weeks.

But Shimpi et al ${ }^{[13]}$ reported statistically significant reductions in FBS, PPBS and HbA1c, in glimepiride and metformin group as compared to glibenclamide and metformin group.

Ortiz et al ${ }^{[10]}$ over a trial of one year duration reported between the glimepiride and metformin combination and glibenclamide and metformin combination groups, where the doses were titrated every 3 months to ensure achievement of glycaemic targets, there were no significant differences between both groups in FBS and PPBS levels throughout the study. At the end of the study, HbA1C concentration was significantly lower in the glimepiride and metformin combination group ( $\mathrm{p}$ value 0.025). A higher proportion of patients from the glimepiride and metformin combination group i.e. $44.6 \%$ as compared to the glibenclamide and metformin combination where only $26.8 \%$ reached the goal of $\mathrm{HbA}_{1 \mathrm{c}}$ of $7 \%$ at the end 12 months of treatment. Sivakumar et al ${ }^{[16]}$ reported over a 6 months trial, glimepiride and metformin combination having statistically significant reductions in PPBS and $\mathrm{HbA}_{1 \mathrm{c}}$ while glibenclamide and metformin combination having statistically significant reductions in FBS as compared to the other group. Among the lipid profile parameters we did not find significant changes in both the two groups but in the glimepiride group the reductions were only slightly numerically better than the glibenclamide group.

Shimpi et al ${ }^{[13]}$ in glimepiride and metformin combination treatment found significant reductions in TC, TG, and LDL-C while there was increase in the HDL-C throughout the study while in glibenclamide and metformin combination group it caused reductions in $\mathrm{TC}, \mathrm{TG}_{\mathrm{s}}$, but not the extent of glimepiride and metformin combination group and there were no changes in LDL-C and HDL-C.

Ortiz et al ${ }^{[10]}$ reported that lipid profile remained without significant changes in both the groups throughout the study where they measured triglycerides and HDL-C.

Sivakumar et al [16] measured only total cholesterol where they found significant reductions in the glimepiride and metformin combination group as compared to glibenclamide and metformin combination group.

In our study the safety and tolerability elicited by both combination groups were consistent with previous studies. Glimepiride and glibenclamidegroup had an overall similar safety profile. The 
most commonly noted adverse events were metallic taste, nausea, vomiting, diarrhoea, hypoglycaemia and abdominal pain. The adverse events were mild and none of the patients from either group discontinued the study drugs because of side effects, there was statistically significant incidence of mild to moderate hypoglycaemic episodes in glibenclamide as compared to glimepiride group.

In Study by Ortiz et al ${ }^{[10]}$ also a higher number of mild and moderate hypoglycaemic events was observed in the glibenclamide and metformin group $(28.9 \%)$ in comparison to the glimepiride and metformin group $(17.1 \%)$. Shimpi et al ${ }^{[13]}$ reported similar occurrence of hypoglycaemic episodes in both the groups.

\section{CONCLUSIONS}

Therefore, we conclude that both groups have similar effect on FBS and HbA1C, whereas glimepiride and metformin combination therapy has superior effect on PPBS level reduction and significantly lesser incidence of hypoglycaemia as compared to glibenclamide and metformin combination group. Increasing evidence support the importance of postprandial hyperglycaemia in glycaemic control with regard to the development of complications in the patients with diabetes. Data also indicates that postprandial hyperglycaemia may have greater effect on the development of cardiovascular complications compared with elevated fasting plasma glucose.

A more intensive approach by using metformin and glimepiride combination therapy in patients with type 2 diabetes mellitus inadequately controlled with metformin, glibenclamide monotherapy may improve the care of patients with diabetes and, ultimately, the outcome of these patients.

However, further long duration studies are required to elucidate long-term effects on glycaemic controls, lipid profile parameters as well as other metabolic parameters.

Acknowledgements: The authors would like to thanks Mangesh Raut for writing support.

\section{REFERENCES}

1. IDF Atlas. International Diabetes Federation. 5th edition. 2011.

2. Powers AC, Alessio DD. Endocrine Pancreas and Pharmacotherapy of Diabetes Mellitus and Hypoglycaemia. Brunton LL, Chabner BA, Knollmann BC, editors. In: Goodman \& Gilman's The Pharmacological Basis of Therapeutics, 12th Edition, New York. McGraw-Hill; 2011: p 1237-1274.

3. Garber AJ, Donovan DS, Dandona P, Bruce S, Park JS. Efficacy of Glyburide/Metformin Tablets Compared with Initial Monotherapy in Type 2 Diabetes. J ClinEndocrinol Metab. 2003; 88:3598-3604

4. Buse JB, Polonsky KS \&Burant CF. Type 2 Diabetes Mellitus. Melmed S, Polonsky KS, Larsen PR, \&Kronenberg H M. In: Williams textbook of endocrinology, 12th edition. Expert consult. Elsevier Health Sciences; 2011:1371-1435.

5. Triplitt CL, Raesner II CA, Isley WL. Diabetes Mellitus. Dipiro TJ, Talbert RL, Yee GC, Matzake GR, Wells BG, Posey LM, editors. In: Pharmacotherapy A Pathophysiologic Approach, 7th edition; McGraw Hill, New York; 2008:12051242.

6. Ripsin C M, Kang $\mathrm{H}$ \& Urban $\mathrm{R}$ J.Management of blood glucose in type 2 diabetes mellitus. Am Fam Physician.2009; 79(1): 29-36.

7. UK Prospective Diabetes Study Group. UKPDS 28: a randomized trial of efficacy of early addition of metformin in sulfonylurea-treated type 2 diabetes. Diabetes Care. 1998; 21(1): 87-92.

8. Charpentier G, Fleury F, Kabir M, Vaur L and Halimi S. Improved glycaemic control by addition of glimepiride to metformin monotherapy in Type 2 diabetic patients, Diabetic Medicine. 2001;18:828834. 
9. Tosi F, Muggeo M, Brun E, Spiazzi G, Perobelli L, Zanolin E, et. al. Combination Treatment with metformin and glibenclamide versus single-drug therapies in type 2 diabetes mellitus: a randomized, double - blind, comparative study . Metabolism. 2003; 52(7):862-

10. Ortiz MG etal.Efficacy of Glimepiride/Metformin combination versus Glibenclamide /Metformin in patients with uncontrolled type 2 diabetes mellitus.Journal of Diabetes and its complications .2008; 371-374.

11. Massi-Benedetti M. Glimerpiride in type 2 diabetes mellitus: A review of the worldwide therapeutic experience. Clinical therapeutics.2003; 25(3): 799-816.

12. American Diabetes Association. (2013). Diagnosis and classification of diabetes mellitus. Diabetes care.2013; 36(Supplement 1): S67-S74.

13. Shimpi RD, Patil PH, Kuchake VG, Ingle PV, Surana SJ, dighore PN. Comparison of effect of metformin in combination with glimepiride and glibenclamide on glycaemic control in patients with type 2 diabetes mellitus. International Journal of Pharmatech Research. 2009;1:50-61.

14. Kalra, S. Aggressive treatment in newly diagnosed diabetes with fixed dose combinations. Medicine. 2012; 22:249253.

15. Nakamura I et al. Possible effects of glimepiride beyond glycemic control in patients with type 2 diabetes: a preliminary report. Cardiovascular diabetology. 2014; 13(15):1-8.

16. Sivakumar R Rafy M Mohan A and Shihab M. Comparative study of efficacy of glimepiride and metformin versus glibenclamide and metformin for type 2 diabetic patients. Scholars Research Library Der Pharmacia Lettre. 2014; 6 (1):78-82. 